\title{
Numerical investigation on the behavior of combining open- channel flow
}

\author{
Nor Azni Shahari ${ }^{1}$, Nor Arif Husaini Norwaza ${ }^{2}$, Iskandar Shah Mohd Zawawi ${ }^{3}$, \\ Nurisha Adrina Mohd Kamarul ${ }^{4}$, Aimi Said \\ 1,2,4,5Faculty of Computer and Mathematical Sciences Universiti Teknologi MARA, Cawangan Negeri Sembilan, Kampus \\ Seremban, Malaysia \\ ${ }^{3}$ Faculty of Computer and Mathematical Sciences, Kompleks Al-Khawarizmi, Universiti Teknologi MARA, Shah Alam, \\ Selangor, Malaysia
}

\begin{tabular}{|c|c|}
\hline Article Info & ABSTRACT \\
\hline Article history: & Open-channel flow is known as fluid flow with an open atmospheric surface. \\
\hline Received Nov 30, 2020 & It has become an important issue especially when measuring the flow rate \\
\hline Revised Jul 7, 2021 & efforts have been made by the previous researchers to investigate the \\
\hline Accepted Jul 14, 2021 & $\begin{array}{l}\text { behavior of water flow. However, most studies on water flow have only been } \\
\text { carried out in a straight prismatic main channel, either in a trapezoidal and }\end{array}$ \\
\hline Keywords: & $\begin{array}{l}\text { rectangular type of channel section with lateral branch of angle of } 90^{\circ} \text {. In this } \\
\text { study, the general equations of combining open-channel flow for trapezoidal }\end{array}$ \\
\hline Channel junction & and $\mathrm{V}$-shaped channels are modified in the form of nonlinear polynomial \\
\hline Momentum principle & $\begin{array}{l}\text { equations. The proposed equations are solved using Newton-Raphson } \\
\text { procedure to determine the unstream flow denth All the computations and }\end{array}$ \\
\hline Numerical method & analysis of the behavior of water flow depth influenced by Froude number \\
\hline V-shaped channel & and flow rate ratio are performed using graphical user interface, which is \\
\hline Water flow & $\begin{array}{l}\text { designed in MATLAB software. Comparative analysis shows that the } \\
\text { modified equations agree well with the experimental data as reported in the } \\
\text { literature. The trapezoidal channel demonstrates the highest value of flow } \\
\text { depth as the Froude number and flow rate ratio increase; thus, it has potential } \\
\text { to avoid water overflow. }\end{array}$ \\
\hline
\end{tabular}

This is an open access article under the CC BY-SA license.

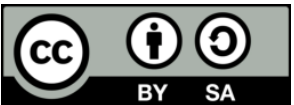

\section{Corresponding Author:}

Nor Azni Shahari

Faculty of Computer and Mathematical Sciences

Universiti Teknologi MARA (UiTM)

Cawangan Negeri Sembilan, Kampus Seremban

Email: norazni@uitm.edu.my

\section{INTRODUCTION}

Water flow is a major natural element that affects our populations, communities, and ecosystems. The hydraulic behavior of open-channel flow depends on the system environments such as the structure elements of the channel and flow condition, which can be divided into three types: critical flow, supercritical flow and subcritical flow [1]. One of the most important structural elements of the system that can be considered is the type of channel's junction. The flow behaves differently at the channel junction due to many complex parameters and variables that must be considered. The estimated increase in the upstream flow depth as a result of lateral flow is one of the important parameters in the channel junction flow [2]. The channel junction can be either a combining channel junction [2]-[6] or a dividing channel junction [1], [7]-[14]. There are many types of channel sections that can be used for the investigation of open channel flow systems. The 
most common channel sections of open channels include those that are trapezoidal, rectangular, triangular, $\mathrm{V}$-shaped, and semi-circular.

The theory of momentum principle and mass continuity equation has been applied to the development of the behavior of water flow to estimate the channel junction's upstream and downstream depth ratio. According to [2] used the momentum principle equation and found that the increase in the flow depth can be predicted when there are undisturbed flow conditions in the channels. Most of the equations of right-angled and short branch channels with equal width have been developed using mass, momentum and energy conservation to determine the upstream depth at the junction [10], [15], [16]. In [17] applied the momentum principle and mass continuity, distinct from the previous study, i.e without assuming equality of the upstream depth and width. Their model pioneered the development of a general nonlinear model based on the theory of momentum with more physical effects such as boundary friction forces and non-right-angle junction.

Rashwan [9] verified the model of two control volumes using the approach of shown in [17] analytically for subcritical dividing steady flow. Furthermore, [18] presented a comparison with the 1D dynamic model proposed by [17] with the 2D model, while [19] made a comparison with the 3D model. Most of the branching channel flow studies have been conducted with a rigid boundary and $90^{\circ}$ branching angle. Normally, the study on channel junction involves a main channel that is a straight prismatic channel with $90^{\circ}$ or not $90^{\circ}$ branching angle. However, [16]-[19] derived a model with different branching junction angles. However, the channels of natural alluvial rivers are usually non prismatic and often curved [20].

Most of the studies are focused on certain types of cross-sectional shape and branching angle. For instance, in [21] elaborated on the influence of the cross-sectional shape (semi circular, rectangular and trapezoidal) of the separation zone in a $90^{\circ}$ junction using large-eddy simulation models to simulate the complex turbulent flow. Pandey and Mishra [22] applied the momentum principle equation to build a mathematical model of the behavior of water flow for trapezoidal and rectangular cross-sectional shape channel junction problems with $30^{\circ}$ and $90^{\circ}$ branching angles. They found out that, in order to pass the same water discharge value with the same bottom width and flow depth through the main channel, the depth ratio for a rectangular channel would be higher than that of the trapezoidal channel. In recent years,

Mohd Zawawi et al. [23] improved the general equation of dividing open-channel flow from [22] to investigate the amount of river flow rate at different bifurcation angles. However, most existing general equations of open-channel flow with various parameters are complicated to be solved. In order to determine the flow depth, it is essential to develop a simplified version of flow equations that can be solved numerically. Therefore, the aim of this study is to derive the equations of combining flow for trapezoidal and $\mathrm{V}$-shape channels in the form of polynomial equations with degree 5 and solve it using Newton-Raphson procedure [24], [25]. The effects of Froude number and flow rate ratio on flow depth for both types of channels are investigated. Further discussions on formulation and implementation are presented in the next sections.

\section{MATHEMATICAL FORMULATIONS}

This section describes the mathematical formulation and theoretical study on the behavior of the combining flow in trapezoidal and V-shaped channels. The combining junction allows the water flow from two branch channels to a single main channel. The behavior of combining flow is determined by applying the mass continuity and momentum principle with the following assumptions: the water flow is one dimensional and parallel to the channel walls, velocity is uniformly distributed immediately along the channel before, inside and after the junction, the friction of the channel wall acting upon the water flow is disregarded, external forces acting upon the water flow, including wind, are disregarded, andthe flow depths in branch channels are equal just before the junction.

The schematic layout and geometric details used for this study are shown in Figure 1. The water is assumed to flow from the branch channel (channel 1 and channel 2) to the main channel (channel 3), where $q$ is the flow rate of the water flow, $b$ is the bottom width of the channel section, $\theta$ is the angle of the branch channel to the axis of the main channel, $y$ is the flow depth of the water flow, $T$ is the top width of the cross-sectional area of the water, $z$ is the side slope value of the channel and $\alpha$ is the side slope angle of the channel from the horizontal line. Each parameter with subscripts 1, 2, and 3 indicates the parameter that belongs to channel 1, channel 2, and channel 3, respectively. The summary of the channels' component equations is shown in Table 1. 


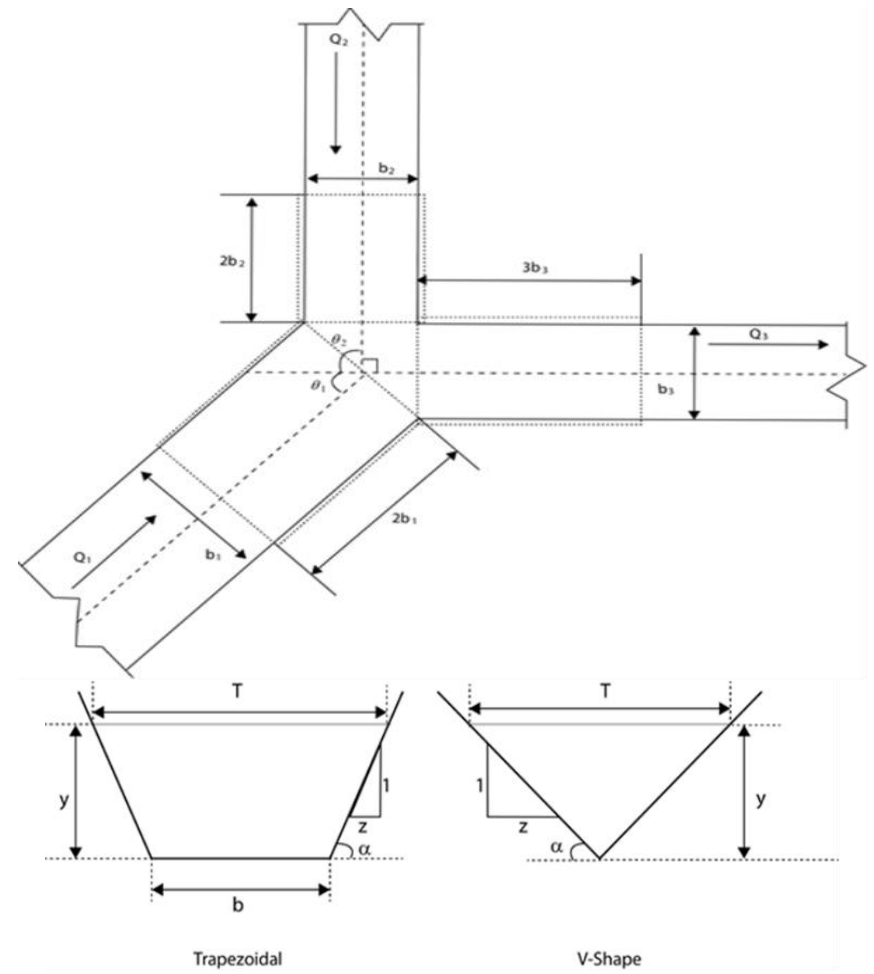

Figure 1. Schematic layout of combining flow junction

Table 1. Channels' component equation

\begin{tabular}{|c|c|c|}
\hline Channel components & Trapezoidal & V-shaped \\
\hline Top Width & $T(y)=b+2 z y$ & $T(y)=2 z y$ \\
\hline Cross-sectional Area & $A(y)=b y+z y^{2}$ & $A(y)=z y^{2}$ \\
\hline Wetted Perimeter & $P_{w}(y)=b+2 y\left(1+z^{2}\right)^{\frac{1}{2}}$ & $P_{w}(y)=2 y\left(1+z^{2}\right)^{\frac{1}{2}}$ \\
\hline Hydraulic Radius & $R_{H}(y)=\frac{b y+z y^{2}}{b+2 y\left(1+z^{2}\right)^{\frac{1}{2}}}$ & $R_{H}(y)=\frac{z y}{2\left(1+\mathrm{z}^{2}\right)^{\frac{1}{2}}}$ \\
\hline $\begin{array}{l}\text { Hydrostatic Force on the Horizontal Strip (at any section) of the Cross-Sectional } \\
\text { Area }\end{array}$ & $P(y)=\gamma\left(\frac{b}{2}+\frac{z y}{3}\right) y^{2}$ & $P(y)=\gamma\left(\frac{z y^{3}}{3}\right)$ \\
\hline
\end{tabular}

\subsection{Simplified equation of water flow for $\mathrm{V}$-shaped channel}

The continuous-momentum principle model based on assumptions of this study is defined by

$$
P_{1} \cos \quad \theta_{1}-P_{3}+\Delta P=\frac{\gamma}{g}\left(Q_{3} V_{3}-Q_{2} V_{2} \cos \theta_{2}-Q_{1} V_{1} \cos \theta_{1}\right)
$$

Solve for L.H.S of (1), where $P_{1}=\gamma\left(\frac{z y_{1}^{3}}{3}\right), P_{3}=\gamma\left(\frac{z y_{3}^{3}}{3}\right)$ and $\Delta P$ is a difference between the pressure force at the junction on the main channels and the pressure force right before that. Since it is assumed that there is no hydraulic jump at the junction, then,

$$
\frac{\gamma z}{3}\left(y_{1}^{3}-y_{3}^{3}\right)
$$

Taking R.H.S of (1) and using the definition of flow rate, then

$$
\frac{\gamma}{g}\left(Q_{3} \frac{Q_{3}}{A_{3}}-Q_{2} \frac{Q_{2}}{A_{2}} \cos \quad \theta_{2}-Q_{1} \frac{Q_{1}}{A_{1}} \cos \theta_{1}\right)=\frac{\gamma Q_{3}^{2}}{g A_{3}}\left[1-\left\{\frac{Q_{2}^{2}}{Q_{3}^{2}\left(\frac{A_{2}}{A_{3}}\right)} \cos \theta_{2}+\frac{Q_{1}^{2}}{Q_{3}^{2}\left(\frac{A_{1}}{A_{3}}\right)} \cos \theta_{1}\right\}\right]
$$


The Froude number, $F_{3}$ of channel 3 is defined as $F_{3}=\frac{Q_{3}}{A_{3} \sqrt{g \frac{A_{3}}{T_{3}}}}$. By substituting $F_{3}$ into (3), the following equations are obtained:

$$
\frac{Q_{3}^{2}}{g A_{3}}=\frac{Q_{3}^{2}}{g\left(\frac{A_{3}^{3}}{A_{3}^{2}}\right)}\left(\frac{T_{3}}{T_{3}}\right)=\left(\frac{Q_{3}^{2} T_{3}}{g A_{3}^{3}}\right)\left(\frac{A_{3}^{2}}{T_{3}}\right)=F_{3}^{2}\left(\frac{A_{3}^{2}}{T_{3}}\right)=F_{3}^{2} \frac{\left(z y_{3}^{2}\right)^{2}}{2 z y_{3}}=F_{3}^{2} \frac{z y_{3}^{3}}{2} .
$$

Reduce the complexity of the equation by using ratio variables. Let $\frac{y_{1}}{y_{3}}=y_{r}$ and $\frac{A_{1}}{A_{3}}=\frac{z y_{1}{ }^{2}}{z y_{3}{ }^{2}}=y_{r}{ }^{2}$ and $y_{2}=y_{1}$ gives $\frac{A_{2}}{A_{3}}=\frac{z y_{2}^{2}}{z y_{3}{ }^{2}}=y_{r}{ }^{2}$. From the definitions of continuity and ratio variable, $\frac{Q_{2}}{Q_{3}}=q_{r}$ and, yields

$$
\gamma F_{3}^{2} \frac{z y_{3}^{3}}{2}\left[1-\frac{1}{y_{r}^{2}}\left(q_{r}^{2} \cos \quad \theta_{2}+\left(1-q_{r}\right)^{2} \cos \theta_{1}\right)\right]
$$

Taking (2) equal with (5),

$$
\frac{\gamma z}{3}\left(y_{1}^{3}-y_{3}^{3}\right)=\gamma F_{3}^{2} \frac{z y_{3}^{3}}{2}\left[1-\frac{1}{y_{r}^{2}}\left\{q_{r}^{2} \cos \theta_{2}+\left(1-q_{r}\right)^{2} \cos \theta_{1}\right\}\right] .
$$

Therefore, the general equation of the behavior of water flow at the combining channel junction (Vshaped) is defined by,

$$
\frac{1}{3}\left(y_{r}^{3}-1\right)=\frac{1}{2} F_{3}^{2}\left[1-\frac{1}{y_{r}^{2}}\left(q_{r}^{2} \cos \theta_{2}+\left(1-q_{r}\right)^{2} \cos \theta_{1}\right)\right] .
$$

Expanding (7),

$$
\frac{1}{3} y_{r}^{3}-\frac{1}{3}=\frac{F_{3}^{2}}{2}-\frac{F_{3}^{2}}{2 y_{r}^{2}}\left(1-q_{r}\right)^{2} \cos \quad \theta_{1} \text {. }
$$

Then, expand (8) and rearrange it to form a polynomial equation:

$$
\frac{2}{3} y_{r}^{5}-\frac{2}{3} y_{r}^{2}-F_{3}^{2} y_{r}^{2}+F_{3}^{2}\left(1-q_{r}\right)^{2} \cos \quad \theta_{1}=0 .
$$

Therefore, the simplified equation of combining flow for $\mathrm{V}$-shaped channel is given by

$$
r\left(y_{r}\right)=\frac{2}{3} y_{r}^{5}+i \cdot y_{r}^{2}+l
$$

where, $r\left(y_{r}\right)=0, i\left(F_{3}\right)=-\left(\frac{2}{3}+F_{3}^{2}\right), l\left(F_{3}, q_{r}, \theta_{1}\right)=F_{3}^{2}\left(1-q_{r}\right)^{2} \cos \theta_{1}$.

\subsection{Simplified equation of water flow for trapezoidal channel}

The general equation of the behavior of water flow at the combining channel junction (trapezoidal) proposed by [22] is defined as follows:

$$
\begin{aligned}
\left(1+2 k_{3}\right)\left[\frac{1}{2}\left(y_{r}^{2}-1\right)+\frac{k_{3}}{3}\left(y_{r}^{3}-1\right)\right] & \\
= & F_{3}^{2}\left(1+k_{3}\right)^{2}\left[1-\frac{\left(1+k_{3}\right)}{y_{r}}\left\{\frac{q_{r}^{2}}{\left(b_{r 2}+k_{3} y_{r}\right)} \cos \theta_{2}+\frac{\left(1-q_{r}\right)^{2}}{\left(b_{r 1}+k_{3} y_{r}\right)} \cos \theta_{1}\right\}\right]
\end{aligned}
$$

where $k_{3}=\frac{z y_{3}}{b_{3}}, b_{r 1}=\frac{b_{1}}{b_{3}}, b_{r 2}=\frac{b_{2}}{b_{3}}$.

Expanding (10), yields

$$
\begin{aligned}
-\frac{F_{3}^{2}\left(1+k_{3}\right)^{3} q_{r}^{2}}{\left(b_{r 2} y_{r}+k_{3} y_{r}^{2}\right)} & \cos \quad \theta_{2}-\frac{F_{3}^{2}\left(1+k_{3}\right)^{3}\left(1-q_{r}\right)^{2}}{\left(b_{r 1} y_{r}+k_{3} y_{r}^{2}\right)} \cos \theta_{1} \\
& =\frac{k_{3}}{3}\left(1+2 k_{3}\right) y_{r}^{3}+\frac{1}{2}\left(1+2 k_{3}\right) y_{r}^{2}-\frac{1}{2}\left(1+2 k_{3}\right)-\frac{k_{3}}{3}\left(1+2 k_{3}\right) \\
& -F_{3}^{2}\left(1+k_{3}\right)^{2}
\end{aligned}
$$


As shown in (11) cannot be solved for any value of angles $\theta_{1}$ and $\theta_{2}$ unless one of them is at $90^{\circ}$

Hence, we need to eliminate one of the trigonometry in the equation. From the case study, we assume the main flow is from channel 1 to channel 3 and consider $0 \leq \theta_{1} \leq 90^{\circ}$ and $\theta_{2}=90^{\circ}$. In (11) is multiplied both sides with $b_{r 1} y_{r}+k_{3} y_{r}^{2}$ to get the (12):

$$
\begin{aligned}
-F_{3}^{2}\left(1+k_{3}\right)^{3}(1 & \left.-q_{r}\right)^{2} \cos \theta_{1} \\
& =\left[\frac{k_{3}}{3}\left(1+2 k_{3}\right) y_{r}^{3}+\frac{1}{2}\left(1+2 k_{3}\right) y_{r}^{2}-\frac{1}{2}\left(1+2 k_{3}\right)-\frac{k_{3}}{3}\left(1+2 k_{3}\right)\right. \\
& \left.-F_{3}^{2}\left(1+k_{3}\right)^{2}\right]\left(b_{r 1} y_{r}+k_{3} y_{r}^{2}\right)
\end{aligned}
$$

Now, expand the equation and rearrange it to form a polynomial equation.

$$
\begin{aligned}
\frac{k_{3}^{2}}{3}\left(1+2 k_{3}\right) y_{r}^{5}+ & {\left[\frac{b_{r 1} k_{3}}{3}\left(1+2 k_{3}\right)+\frac{k_{3}}{2}\left(1+2 k_{3}\right)\right] y_{r}^{4}+\frac{b_{r 1}}{2}\left(1+2 k_{3}\right) y_{r}^{3} } \\
& +\left[-\frac{k_{3}}{2}\left(1+2 k_{3}\right)-\frac{k_{3}^{2}}{3}\left(1+2 k_{3}\right)-F_{3}^{2}\left(1+k_{3}\right)^{2} k_{3}\right] y_{r}^{2} \\
& +\left[-\frac{b_{r 1}}{2}\left(1+2 k_{3}\right)-\frac{b_{r 1} k_{3}}{3}\left(1+2 k_{3}\right)-F_{3}^{2}\left(1+k_{3}\right)^{2} b_{r 1}\right] y_{r} \\
& +F_{3}^{2}\left(1+k_{3}\right)^{3}\left(1-q_{r}\right)^{2} \cos \quad \theta_{1}=0 .
\end{aligned}
$$

Therefore, the simplified of (13) is (14)

$$
r\left(y_{r}\right)=f \cdot y_{r}^{5}+g \cdot y_{r}^{4}+h \cdot y_{r}^{3}+i \cdot y_{r}^{2}+j \cdot y_{r}+l,
$$

where,

$$
\begin{aligned}
& r\left(y_{r}\right)=0, f\left(k_{3}\right)=\frac{k_{3}^{2}}{3}\left(1+2 k_{3}\right), g\left(k_{3}, b_{r 1}\right)=\left[\frac{b_{r 1}}{3}+\frac{1}{2}\right]\left(k_{3}\right)\left(1+2 k_{3}\right), h\left(k_{3}, b_{r 1}\right) \\
& =\frac{b_{r 1}}{2}\left(1+2 k_{3}\right), i\left(k_{3}, F_{3}\right)=\left(-k_{3}\right)\left[\left(\frac{k_{3}}{3}+\frac{1}{2}\right)\left(1+2 k_{3}\right)+F_{3}^{2}\left(1+k_{3}\right)^{2}\right] \text {, } \\
& j\left(k_{3}, b_{r 1}, F_{3}\right)=\left(-b_{r 1}\right)\left[\left(\frac{k_{3}}{3}+\frac{1}{2}\right)\left(1+2 k_{3}\right)+F_{3}^{2}\left(1+k_{3}\right)^{2}\right], l\left(k_{3}, F_{3}, q_{r}, \theta_{1}\right)=F_{3}^{2}\left(1+k_{3}\right)^{3}(1- \\
& \left.q_{r}\right)^{2} \cos \theta_{1} \text {. }
\end{aligned}
$$

\subsection{Graphical user interface (GUI) in MATLAB programming}

The graphical user interface (GUI) using MATLAB programming has been used in this study to calculate the domain data and compare the behavior of water flow based on the graph. GUI is divided into two parts as shown in Figure 2. The left-hand side is the first part of the system, where the system displays a platform that allows the user to manually input the values of all data.

The radio button function is to select the channel type for either the trapezoidal channel or V-shaped channel. The calculate button will calculate the value of the polynomial equation based on the input values. This state of equation is the new simplified version of the general equation of the behavior of water flow at the combining channel junction. To solve the general equation, the user needs to perform Newton's method on the equation by defining the tolerance value (Tol) and maximum number of iterations (NOI) at the provided text editors before pushing the approximate button. Another output platform displays all the roots of the polynomial. It consists of five roots if the polynomial is in degree five for the trapezoidal channel. The value will be displayed right after the approximate button has been clicked. All the values will be displayed at the same time with the final output, which includes predicted flow depth ratio of channel 1 to channel $3\left(y_{r}\right)$, predicted depth for channel $1\left(y_{1}\right)$ and the number of iterations (NOI) involved in the numerical method. The second part of the system lies at the right-hand side of the GUI. It displays a platform that shows a Cartesian graph representing the pattern behavior of water flow at the combining channel junction. The graph is mainly about the relationship between some variables including $F_{3}$, flow rate ratio of channel 2 and channel $3\left(q_{r}\right)$, angle of channel 1 from the channel 3 axis $\left(\theta_{1}\right)$ and the flow depth of channel $3\left(y_{3}\right)$, which is represented by the $\mathrm{x}$-axis and its effect on $y_{r}$, which is represented by the $\mathrm{y}$-axis. 

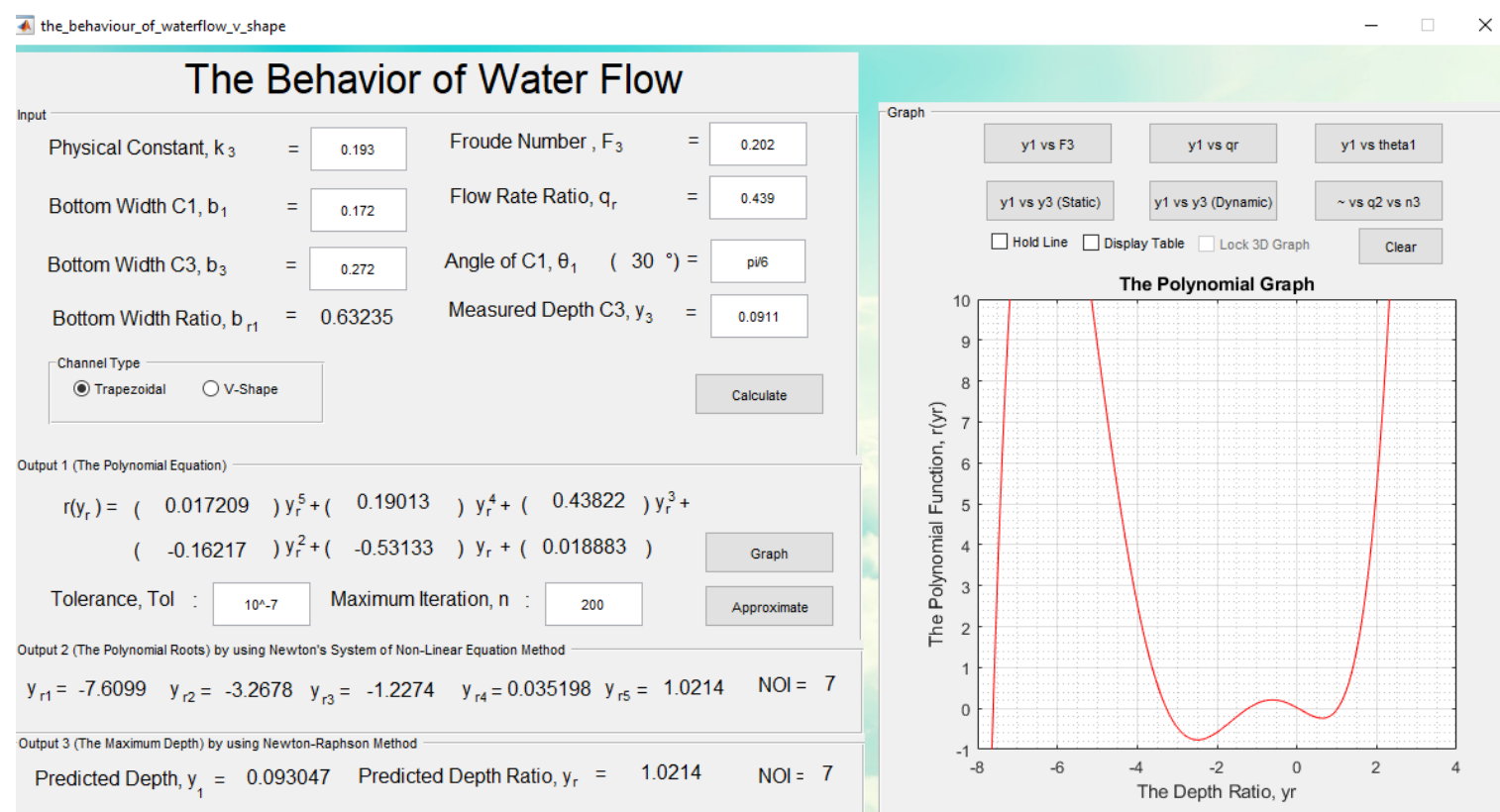

Figure 2. Graphical user interface for combining flow

\section{RESULTS AND ANALYSIS}

Table 2 shows the geometrical details and Table 3 shows the experimental and measured hydraulic details of the trapezoidal channel used by [22]. It can be seen from Table 2 for the trapezoidal channel, that the bottom width, $b$ of all channels has been kept different. Further, the branching angle of the branch channel 1 and branch channel 2 has been kept at $30^{\circ}$ and $90^{\circ}$ respectively to the axis of channel 3. Table 3 shows that there are four parameters involved, which include the $F_{3}, q_{r}$ and measured depth $\left(y_{1}\right.$ and $\left.y_{3}\right)$. The side slope times flow depth to bottom width ratio is also a part of the experimental and measured hydraulic details.

Table 2. Geometrical characteristics of the channels

\begin{tabular}{lcccccc}
\hline Channel & \multicolumn{3}{c}{ Trapezoidal } & \multicolumn{3}{c}{ V-Shaped } \\
\hline Bottom width $(\mathrm{m}), b$ & 0.172 & 0.072 & 0.272 & $\mathrm{NA}$ & $\mathrm{NA}$ & NA \\
$\begin{array}{l}\text { The combining angle from the } \\
\begin{array}{l}\text { direction of flow in main } \\
\text { channel, } \theta\end{array}\end{array}$ & $30^{\circ}$ & $90^{\circ}$ & $\mathrm{NA}$ & $30^{\circ}$ & $90^{\circ}$ & NA \\
\end{tabular}

Table 3. Experimental and measured characteristics of the channels

\begin{tabular}{lrrrrrrr}
\hline \multicolumn{1}{c}{ Experiments $(E)$ Hydraulics } & \multicolumn{3}{c}{ Trapezoidal [22] } & \multicolumn{3}{c}{ V-shaped } \\
& E1 & E2 & E3 & E1 & E2 & E3 \\
\hline The side slope x flow depth to bottom width ratio of channel 3, $k_{3}$ & 0.193 & 0.170 & 0.197 & NA & NA & NA \\
Froude number of channel 3, $F_{3}$ & 0.202 & 0.278 & 0.365 & 0.202 & 0.278 & 0.365 \\
Flow rate ratio of channel 2 to channel 3, $q_{r}$ & 0.439 & 0.500 & 0.875 & 0.439 & 0.500 & 0.875 \\
Measured flow depth of channel 3, $y_{3}$ & 0.0911 & 0.801 & 0.0926 & 0.0911 & 0.801 & 0.0926 \\
Measured flow depth of channel 1, $y_{1}$ & 0.0945 & 0.0838 & 0.1053 & - & - & - \\
\hline
\end{tabular}

\subsection{Experiment validation}

Three sets of experimental data (E1, E2 and E3) are taken from [22] to validate the predicted flow characteristic of trapezoidal channels obtained from (14). In Table 4, the results show a very good agreement between experiment and predicted $y_{1}$ with estimated error $1.54 \%, 0.009 \%$ and $2.57 \%$. It shows that the predicted $y_{1}$ produced by the proposed equation matches very well with the experimental data. 
Table 4. Comparison of flow depth between experiment and numerical method

\begin{tabular}{lcccccc}
\hline Experiments $(\mathrm{E})$ & \multicolumn{2}{c}{ Trapezoidal [22] } & \multicolumn{3}{c}{ V-shaped } \\
Hydraulics & E1 & E2 & E3 & E1 & E2 & E3 \\
\hline Flow depth of channel 1, $y_{1}$ (Experiment) & 0.0945 & 0.0838 & 0.1053 & NA & NA & NA \\
Depth ratio, $y_{r}$ (Predicted) & 1.0214 & 1.0461 & 1.1058 & 1.0148 & 1.0299 & 1.0619 \\
Flow depth of channel 1, $y_{1}$ (Predicted) & 0.093047 & 0.083792 & 0.1024 & 0.092447 & 0.082491 & 0.098332 \\
Relative error $(\%)$ & $1.54 \%$ & $0.009 \%$ & $2.57 \%$ & - & - & - \\
\hline
\end{tabular}

\subsection{Sensitivity analysis of flow depth ratio $\left(y_{r}\right)$ on trapezoidal and $\mathbf{V}$-shape channel}

The sensitivity to flow depth reflects the degree to which the changes in Froude number and flow rate can affect the flow depth. For each parameter, the E3 data in Table 3 are added and reduced by 0.25. Figures 3 and Figure 4 depict the graphical representation of $F_{3}$ and $q_{r}$ to the polynomial root, $y_{r}$ for trapezoidal channels, respectively.

In Figure 3, it is undeniable that changes in $F_{3}$ shows the biggest gap with the required root, while in Figure 4, it is obvious that $q_{r}$ shows a larger gap with the value of root, but slightly smaller compared to the gap made by $F_{3}$. Subsequently, the effects of $F_{3}$ and $q_{r}$ to the polynomial root, $y_{r}$ for $\mathrm{V}$-shaped channels are illustrated in Figures 5 and Figure 6.

It can be seen clearly that the pattern of the results (Figures 3-6) is similar to that of [10] and [22], in which the main factors to have an effect on the water depth in the branch channel system are the flow rate ratio and Froude number. Furthermore, the side slope times flow depth to the bottom width ratio of channel 3 $\left(k_{3}\right)$, the bottom width ratio of channel 1 to channel $3\left(b_{r 1}\right)$ and the value of the angle of channel $1\left(\theta_{1}\right)$ are slightly affected and difficult to identify.

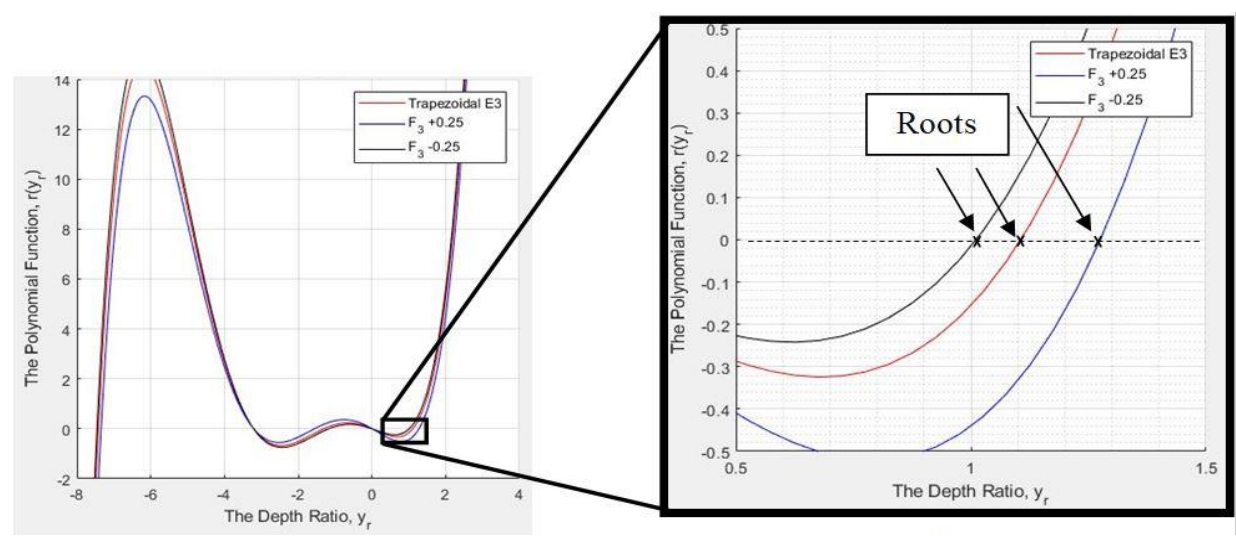

Figure 3. The effect of $F_{3}$ to the polynomial root, $y_{r}$ for trapezoidal channel

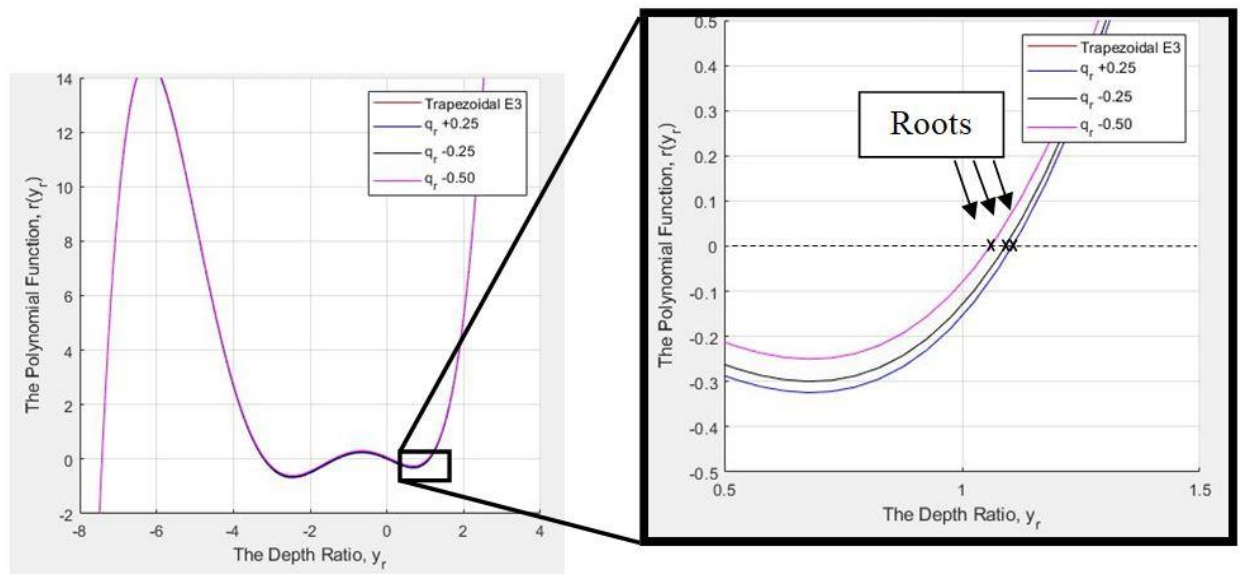

Figure 4. The effect of $q_{r}$ to the polynomial root, $y_{r}$ for trapezoidal channel 


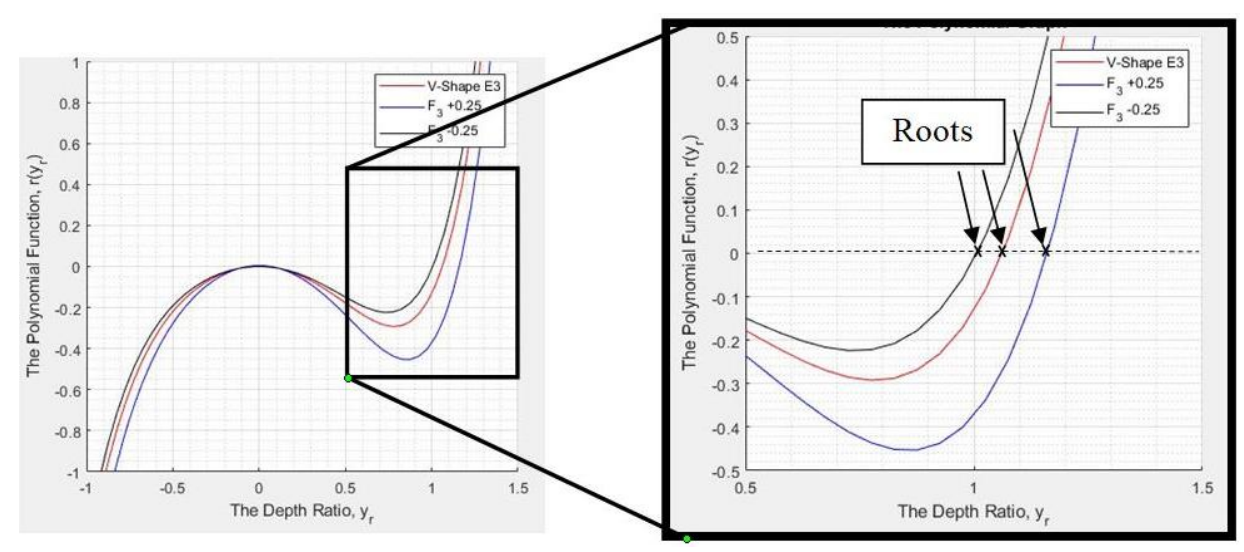

Figure 5. The effect of $F_{3}$ to the polynomial root, $y_{r}$ for $\mathrm{V}$-shaped channel

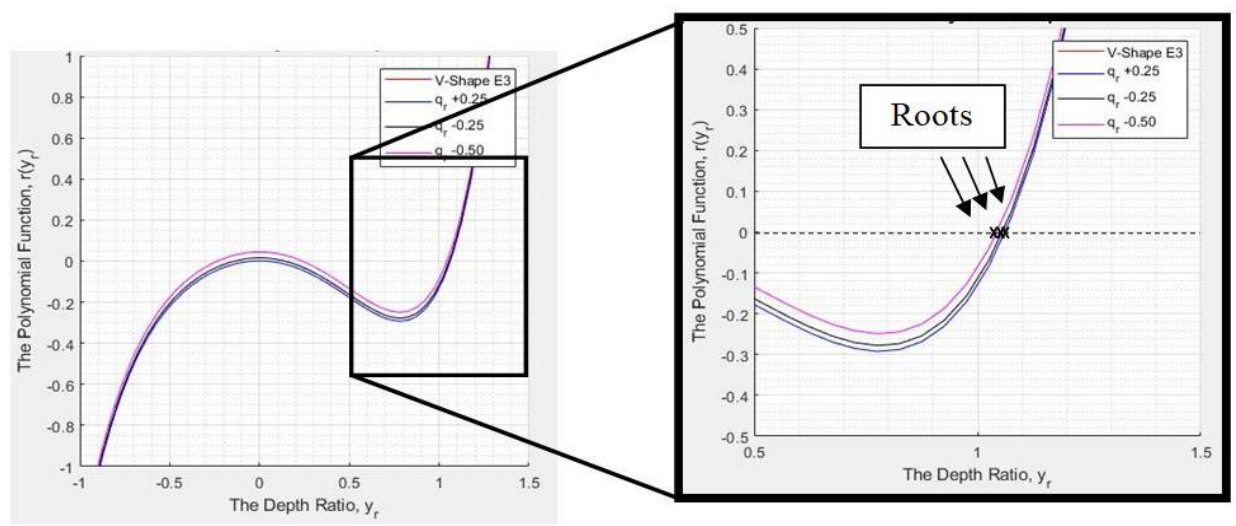

Figure 6. The effect of $q_{r}$ to the polynomial root, $y_{r}$ for $\mathrm{V}$-shaped channel

In conclusion, $F_{3}$ plays the major role in determining the maximum $y_{1}$ to avoid the overflow of water in both Trapezoidal and V-shape channels. This supports the result by [12] that states the nonlinear models are more sensitive to $F_{3}$. This is rational because the inflow water obviously depends on the condition of the water flow at the outflow water. It reacts differently, depending on the behavior of the water flow, where the flow may be subcritical ( $F<1$ ), critical $(F=1)$, or supercritical $(F>1)$. Besides, $q_{r}$ plays the second most important part in determining the value of $y_{1}$. This happens because the $q_{r}$ highly depends on the hydraulic velocity of the water flow, $V$ and the cross-sectional area of the water flow, $A$. Thus, the change in $q_{r}$ affects the maximum $y_{1}$. Lastly, it is obvious that $\theta_{1}$ has a minimal effect on the behavior of water flow in the water flow system.

\subsection{Comparison between Trapezoidal and $\mathrm{V}$-shaped channel junction to the depth ratio $y_{r}$}

The parametric investigation of two parameters, $F_{3}$ and $q_{r}$ is made in order to analyse the effect of parameters on $y_{r}$ in both trapezoidal and V-shaped channels. The E3 data in Tables 2 and 3 are used as fixed variables. The property values of other cases are obtained by varying each parameter, whilst keeping the other value constant. Figures 7 and 8 illustrate the effect of $F_{3}$ and $q_{r}$ on $y_{r}$ respectively.

Figure 7 shows that the trapezoidal channel has the highest value of $y_{r}$ with a value of 1.6 compared to 1.35 for the $\mathrm{V}$-shaped channel as $F_{3}$ increases. In Figure 8, the highest value of $y_{r}$ is 1.12 for the trapezoidal channel and 1.06 for the V-shaped channel with the increase of $q_{r}$. Overall, as both parameter increase, the rate of increase in $y_{r}$ is higher for the trapezoidal channel compared to the $\mathrm{V}$-shaped channel. The increase of $y_{r}$ with the observation of equal upstream depth, $y_{1}=y_{2}$ is consistent as shown in the previous studies [12], [17]. 


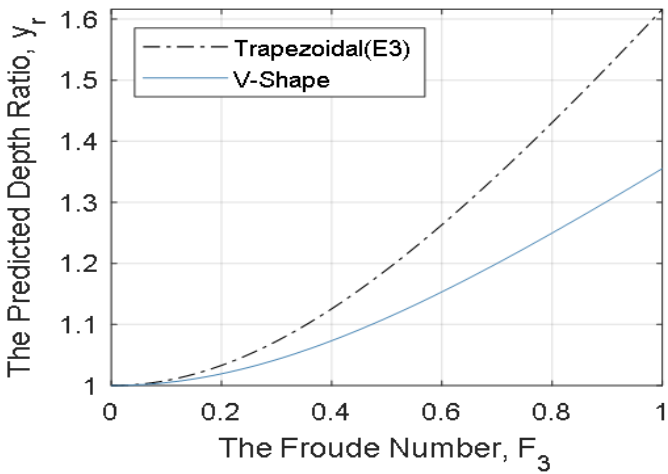

Figure 7. The effect of $F_{3}$ on $y_{r}$

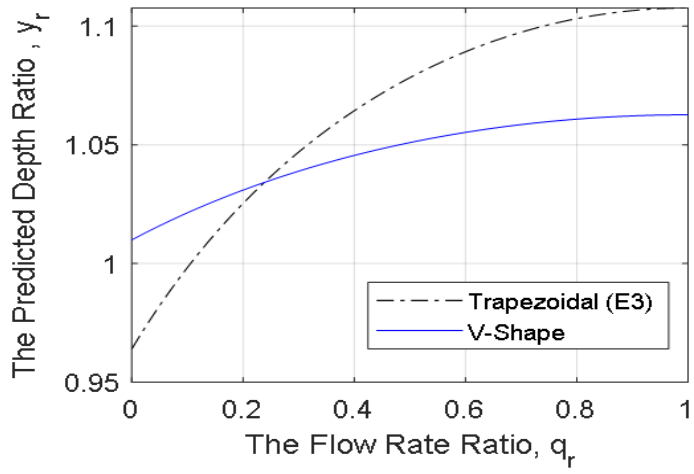

Figure 8. The effect of $q_{r}$ on $y_{r}$

\section{CONCLUSION}

The general equations of open-channel flow for the types of trapezoidal and V-shaped crosssectional channels have been developed in the form of polynomial equations with degree five by taking into account two branch channels that unite, forming a single main channel. The modified equations consist of five parameters, which represent both physical and flow characteristics of the water. The parametric investigation has been carried out to understand the interdependence of some of the responding variables, where the Froude number gives the greatest impact on the water flow depth. Furthermore, the rate of increase of depth flow for the trapezoidal channel is higher than the V-shaped channel as the Froude number and flow rate ratio increase. Therefore, the trapezoidal channel is recommended to avoid water overflow in the combining open-channel flow. Nevertheless, this study relates only to combining open-channel flow. Thus, the modified equation of dividing flow for trapezoidal and V-shaped channels may be considered for future research.

\section{REFERENCES}

[1] G. Kesserwani, J. Vazquez, N. Riviere, Q. Liang, G. Travin, and R. Mose, "New Approach for Predicting Flow Bifurcation at Right-Angled Open-Channel Junction," Journal of Hydraulic Engineering, vol. 136, no. 9, pp. 662-668, 2010, doi: 10.1061/(ASCE)HY.1943-7900.0000222.

[2] A. S. Ramamurthy, L. B. Carballada, and D. M. Tran, "Combining Open Channel Flow at Right Angled Junctions," Journal of Hydraulic Engineering, vol. 114, no. 12, pp. 1449-1460, 1988, doi: 10.1061/(ASCE)07339429(1988)114:12(1449).

[3] A. K. Pandey and P. K. Mohapatra, "3D simulation of flow In a right angled channel junction with a pit," in World Environmental and Water Resources Congress 2019: Hydraulics, Waterways, and Water Distribution Systems Analysis, Pittsburgh, Pennsylvania, 2019, pp. 144-158, doi: 10.1061/9780784482353.014.

[4] S. K. Biswal, P. Mohapatra, and K. Muralidhar, "Hydraulics of combining flow in a right-angled compound open channel junction," Sadhana, vol. 41, no. 1, pp. 97-110, 2016, doi: 10.1007/s12046-015-0442-y.

[5] L. Schindfessel, S. Creelle, and T. De Mulder, "Flow Patterns in an Open Channel Confluence with Increasingly Dominant Tributary Inflow," Water, vol. 7, pp. 4724-4751, 2015, doi: 10.3390/w7094724.

[6] S. I. Shakil, M. J. Uddin, and C. Mondol, "Numerical modelling of flow in a $90^{\circ}$ channel confluence," in the International Conference on Civil Engineering for Sustainable Development(ICCESD 2020), KUET, Khulna, Bangladesh, 2020, pp. 1-8.

[7] V. S. Neary and A. J. Odgaard, "Three-dimensional flow structure at open-channel diversions," Journal of Hydraulic Engineering, vol. 119, no. 11, pp. 1223-1230, 1993, doi: 10.1061/(ASCE)0733-9429(1993)119:11(1223.

[8] A. S. Ramamurthy, J. Qu, and D. Vo, "Numerical and Experimental Study of Dividing Open-Channel Flows," Journal of Hydraulic Engineering, vol. 133, no. 10, pp. 1135-1144, 2007, doi: 10.1061/(ASCE)07339429(2007)133:10(1135).

[9] I. M. H. Rashwan, "Dynamic Model for Subcritical Dividing Flows in open Channel Junction," in Eighth International Water Technology Conference, IWTC8 2004, Alexandria, Egypt, 2004, pp. 511-520.

[10] C.-C. Hsu, C.-J. Tang, W.-J. Lee, and M.-Y. Shieh, "Subcritical $90^{\circ}$ Equal-Width Open-Channel Dividing Flow," Journal of Hydraulic Engineering, vol. 128, no. 7, pp. 716-720, 2002, doi: 10.1061/(ASCE)07339429(2002)128:7(716).

[11] Barkdoll, Brian D., B. L. Hagen, and A. J. Odgaard, "Experimental Comparison Of Dividing Open-Channel Withduct Flow In T-Junction," Journal of Hydraulic Engineering, vol. 124, no. 1, pp. 92-95, 1998, doi: 10.1061/(ASCE)0733-9429(1998)124:1(92).

[12] G. Kesserwani, R. Ghostine, J. Vazquez, R. Mosé, M. Abdallah, and A. Ghenaim, "Simulation of subcritical flow at openchannel junction," Advances in Water Resources, vol. 31, no. 2, pp. 287-297, 2008, doi: 10.1016/j.advwatres.2007.08.007. 
[13] R. Ghostine, J. Vazquez, A. Terfous, R. Mose, and A. Ghenaim, "Comparative study of 1D and 2D flow simulations at open-channel junctions," Journal of Hydraulic Research, vol. 50, no. 2, pp. 164-170, 2012, doi: 10.1080/00221686.2012.661563.

[14] K. El Kadi Abderrezzak, L. Lewicki, A. Paquier, N. Rivière, and G. Travin, "Division of critical flow at threebranch open-channel intersection," Journal of Hydraulic Research, vol. 49, no. 2, pp. 231-238, 2011, doi: 10.1080/00221686.2011.558174.

[15] C.-C. Hsu, F.-S. Wu, and W.-J. Lee, "Flow at $90^{\circ}$ Equal-width Open Channel Junction," Journal of Hydraulic Engineering, vol. 124, no. 2, pp. 186-191, 1998, doi: 10.1061/(ASCE)0733-9429(1998)124:2(186).

[16] S. K. Gurram, K. S. Karki, and W. H. Hager, "Subcritical Junction Flow," Journal of Hydraulic Engineering, vol. 123, no. 5, pp. 447-455, 1997, doi: 10.1061/(ASCE)0733-9429(1997)123:5(447).

[17] S. A. Shabayek, P. Steffler, and F. Hicks, "Dynamic Model for Subcritical Combining Flows in Channel Junctions," Journal of Hydraulic Engineering, vol. 128, pp. 821-828, 2002, doi: 10.1061/(ASCE)07339429(2002)128:9(821).

[18] R. Ghostine, J. Vazquez, A. Terfous, N. Rivière, A. Ghenaim, and R. Mosé, "A comparative study of 1D and 2D approaches for simulating flows at right angled dividing junctions," Applied Mathematics and Computation, vol. 219, no. 10, pp. 5070-5082, 2013, doi: 10.1016/j.amc.2012.11.048.

[19] H. Luo, D. K. Fytanidis, A. R. Schmidt, and M. H. García, "Comparative 1D and 3D numerical investigation of open-channel junction flows and energy losses," Advances in Water Resources, vol. 117, pp. 120-139, 2018, doi: 10.1016/j.advwatres.2018.05.012.

[20] B. C. Yen, "Open Channel Flow Resistance," Journal of hydraulic engineering, vol. 128, no. 1, pp. 20-39, 2002, doi: 10.1061/(ASCE)0733-9429(2002)128:1(20).

[21] L. Schindfessel, S. Creëlle, and T. De Mulder, "How Different Cross-Sectional Shapes Influence the Separation Zone of an Open-Channel Confluence," Journal of Hydraulic Engineering, vol. 143, no. 9, p. 040170362017 , doi: 10.1061/(ASCE)HY.1943-7900.0001336.

[22] A. K. Pandey and R. Mishra, "Comparison of Flow Characteristics at Rectangular and Trapezoidal Channel Junctions," Journal of Physics: Conference Series, vol. 364, no. 1, pp. 1-11, 2012, doi: 10.1088/17426596/364/1/012141.

[23] I. S. Mohd Zawawi, N. L. Abdullah, H. Aris, B. A. Jaafar, N. A. H. Norwaza, and M. H. F. Mohd Yunos, "Mathematical Modeling for Flood Mitigation: Effect of Bifurcation Angles in River Flowrates," Civil Engineering and Architecture vol. 7, no. 6A, pp. 50-57, 2019, doi: 10.13189/cea.2019.071406.

[24] A. Golikov, Y. G. Evtushenko, and N. Mollaverdi, "Application of Newton's Method for Solving Large Linear Programming Problems," Computational Mathematics and Mathematical Physics, vol. 44, no. 9, pp. 1484-1493, 2004.

[25] R. Gupta, V. Sawarkar, and P. Bhave, "Application of Newton-Raphson Method in Optimal Design of Water Distribution Networks," Journal Indian Waterworks Association, vol. 35, no. 1, pp. 31-31, 2003. 